\title{
A novel technique for dacryocystorhinostomy tube insertion
}

\author{
İbrahim Cukurova', ilker Burak Arslan' ${ }^{1}$, Anıl Hışmi' ${ }^{2}$ Suphi Bulgurcu ${ }^{3}$, Erdem Atalay Cetinkaya' \\ ${ }^{1}$ University of Health Science Head \& Neck Surgery Clinic, Istanbul, Turkey \\ ${ }^{2}$ SBU Tepecik Research and Education Hospital Head \& Neck Surgery Clinic, Izmir, Turkey \\ ${ }^{3}$ İstanbul Sultan Abdulhamid Research and Education Hospital Head \& Neck Surgery Clinic, Istanbul, Turkey
}

\section{ABSTRACT}

OBJECTIVE. The purpose of this paper is to describe a simple and safer silicone tube insertion technique in endoscopic dacryocystorhinostomy.

MATERIAL AND METHODS. In our technique, steel wire is inserted into a rigid suction tube (3 mm in diameter) immediately after the medial wall of the sac under endoscopic view. The duration of retrieving the wire from the sac and out of the nasal passage, the number of mucosal lacerations and bleeding were compared with conventional methods such as using retrieval device or forceps.

RESULTS. The duration of retrieving the wire from the sac and out of the nasal passage and mucosal laceration were statistically reduced $(\mathrm{P}<0.05)$ in this novel technique when compared with other methods.

CONCLUSION. Sheltering the sharp end of the wire with a suction cannula is a safe and easy method without using any additional tools

KEYWORDS: dacryocystorhinostomy, endoscopy, silicone, tube.

\section{INTRODUCTION}

A dacryocystorhinostomy (DCR) procedure involves the removal of the lacrimal and maxillary bone adjacent to the nasolacrimal sac, and incorporating the lacrimal sac with the lateral nasal mucosa in order to bypass the obstruction of the nasolacrimal duct. In order to maintain the long-term patency of the DCR ostium, in both endonasal and external techniques, a bicanalicular silicone tube is used $^{1}$. Both ends of the tube are provided with a stainless-steel wire, which serves as a metallic introducer into the new passage way to cannulate the canaliculi and the lacrimal sac. The length of the wire differs according to the hardness of the steel it is made of. The wire-guided bicanalicular silicone tube is inserted into the sac via two punctures, and then passed through the ostium achieved in the medial wall of the sac. In the conventional technique, both ends of the wire are gripped at the rhinostomy side using retrieval device or forceps ${ }^{2}$.

Potential complications related to bicanalicular silicone tube insertion may be represented by the injury to the adjacent tissue in the probed area, bleeding from the nasal mucosa and sometimes the middle turbinate; the septal mucosa and/or the cartilage may be injured during wire insertion, because it is difficult to retrieve the long metal probe inside the nasal cavity through the entrance of the puncture to the nasal vestibule, which includes several twists.

In this report, we present a new atraumatic silicone tube insertion method.

\section{MATERIAL AND METHODS}

We compared our new technique with the conventional procedure. An informed consent of all patients was taken before surgery. After approval of 


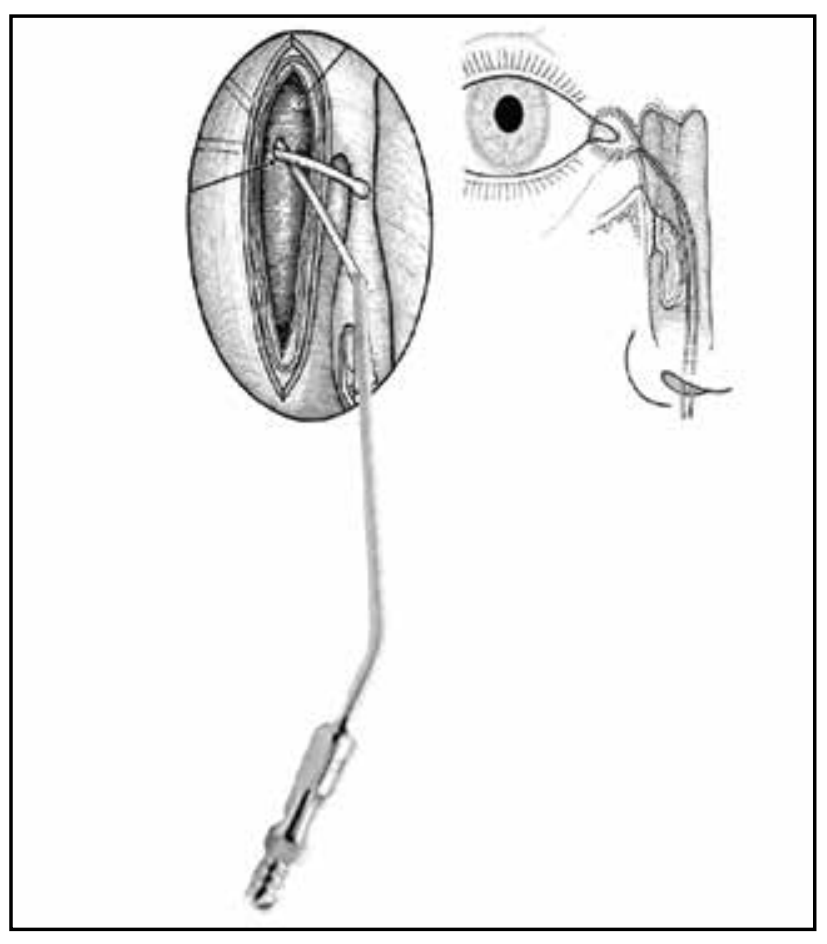

Figure 1. Schematization of the new technique.

the local ethic committee (2018/01), two groups of 20 patients who were operated between January 2012 and November 2017 were included into the study. For the patients included in Group A we used our new technique for the lacrimal stenting and for those in Group B one conventional method including retrieval device or forceps was performed. Both groups' operation videos were analysed by three otolaryngologists. The duration of retrieving the wire from the sac and out of the nasal passage, the number of mucosal lacerations, and bleeding were noted separately for both groups. Patients were followed for at least one year.

\section{Description of the new surgical technique}

After dilation of both punctures, the steel wire attached to the silicone tube was passed through the upper or lower canaliculi. The lacrimal sac was opened with a sickle knife or cutting forceps. When the steel wire ending achieved the perforated medial wall of the lacrimal sac, a $3 \mathrm{~mm}$ suction tube was inserted into the neopassage (Figures 1, 2). The distal end of the wire was inserted into the suction tube and the proximal end of the wire was pushed through the nasal passage without contacting the nasal mucosa, under endoscopic view. The same procedure was repeated for the other canaliculi. Finally, the ends of the silicone tubes were cut and tied.

Statistical analysis of data was made by using the

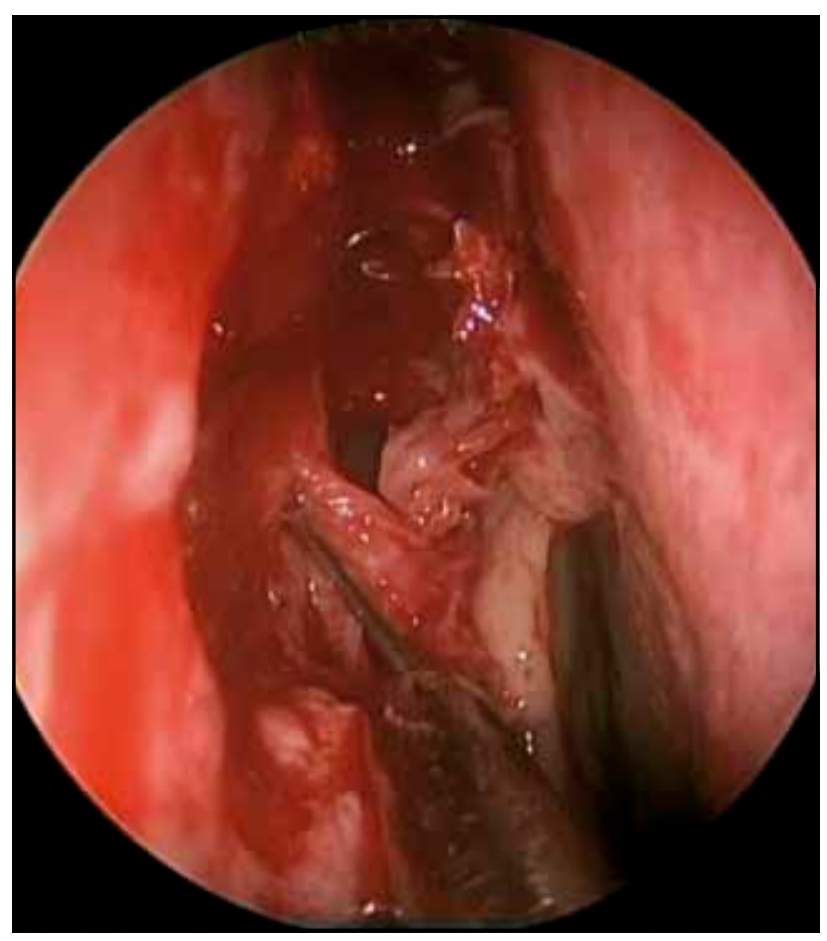

Figure 2. The distal end of the wire was inserted into the $3 \mathrm{~mm}$ suction tube while under endoscopic view.

SPSS $^{\circledR} 20.0$ software (SPSS Inc., Chicago, IL, USA). Pearson Chi-Square test method and the Fisher-exact test were used for the determination of the association between the two study groups. Statistically, $\mathrm{p}<0.05$ was accepted as significant.

\section{RESULTS}

There was no statistically significant difference observed between both groups by age and gender $(p>0.05)$. The number of mucosal lacerations observed was 1 in group A and 9 in group B $(p=0.003$, $p<0.05)$. Bleeding during tubing was determined as 1 in group A and 5 in group B $(p=0.077, p>0.05)$.

The duration of wire retrieval was significantly less in group A compared to group B $(p=0.016$, $p<0.05$ ) (Table 1 ).

The one-year postoperative follow-up did not reveal any significant difference (between the two types of intervention) in the dacryocystorhinostomy patency and the improved epiphora $(p>0.05)$ (Table 1$)$.

\section{DISCUSSIONS}

Insertion of the silicone tube with a double metallic loader may cause some complications such as corneal abrasion, canalicular or punctal slitting, 


\section{Table 1}

Number of mucosal lacerations, bleeding, duration of retrieving the wire from the sac and out of the nasal passage, surgical success at the end of the one-year follow-up.

\begin{tabular}{ccccc}
\hline & Mucosal laceration & Bleeding & $\begin{array}{c}\text { Duration of wire } \\
\text { retrieval (sec) }\end{array}$ & $\begin{array}{c}\text { Surgical success at one- } \\
\text { year follow-up }\end{array}$ \\
\hline New technique (Group A) & 1 & 1 & 7.55 & 19 \\
\hline Conventional technique (Group B) & 9 & 5 & 12.6 & 18 \\
\hline p-value & 0.003 & 0.077 & 0.016 & 0.548 \\
\hline
\end{tabular}

granuloma formation in the nose and lacrimal fossa, injury of the nasal mucosa, and nasal bleeding ${ }^{2,3}$. Injury of the nasal mucosa causes bleeding, which results in synechia and difficult intra-operative visualization. Synechia between the lateral wall and the middle turbinate is one of the reasons for endoscopic DCR failure ${ }^{4,5}$. At the same time, avoiding mucosal laceration decreases nasal crusting and improves post-operative healing.

Covering the wires with a suction tube prevents undesired contact with the nasal mucosa. Under the endoscopic view, the wire should be easily inserted into the cannula. Also, pushing the wire from its proximal end is safer for eye protection than pulling it out. Catching the steel wire with retrieval device or forceps - usually Blakesley forceps - is a simple technique, but the wire usually gets away and causes mucosal laceration. At the same time, slipped wires may create a corneal injury via its proximal end when the control of the distal end is loose, because the steel wire bends while passing through the bony neoostium and displays a spring effect due to the angulations of its course.

Although our new technique has no direct effect on long-term patency of dacryocystorhinostomy, according to the study results, it can improve the surgical outcome via early mucosal healing and lesser crusting.

\section{CONCLUSIONS}

Our new technique precludes the steel bouncing in two ways without any additional tools. Once the wire is covered with suction, it prevents slipping. Secondly, pushing the steel from its proximal end is more controlled. The stretched steel wire is safely kept in suction; thus, the surgeon can prevent crusting, which may delay healing in the early post-operative period, and synechia, which may cause a recurrence of epiphora in the late postoperative period.
Conflict of interest: The authors have no conflict of interest.

Financial disclosure: The authors declared that this study has received no financial support.

Acknowledgements: None

Contribution of authors: All contributors meet the criteria for authorship.

\section{REFERENCES}

1. Jyothi AC, Ajar K, Prawahar C. Endoscopic dacryocystorhinostomy: our experience. Int $\mathrm{J}$ Otorhinolaryngol Head and Neck Surg. 2016;2(4):254-7.

2. Pakdel F. Silicone intubation does not improve the success of dacryocystorhinostomy in primary acquired nasolacrimal duct obstruction. J Ophthalmic Vis Res. 2012;7(3):271-2.

3. Tanigawa T, Sasaki H, Nonoyama H, Horibe Y, Nishimura K, Hoshino T, et al. Outcomes of endoscopic endonasal dacryocystorhinostomy for intractable lacrimal dacryostenosis and associated factors. Int J Ophthalmol. 2016;9(10):1471-5. DOI: 10.1824/ijo.2016.10.17.

4. Onerci M, Orhan M, Ogretmenoglu O, Irkec M. Long-term results and reasons for failure of intranasal endoscopic dacryocystorhinostomy. Acta Otolaryngol. 2000;120(2):319-22.

5. Prakash MD, Viswanatha B, Rasika R. Powered endoscopic endonasal dacryocystorhinostomy with mucosal flaps and trimming of anterior end of middle turbinate. Indian J Otolaryngol Head Neck Surg. 2015;67(4):333-7. DOI: 10.1007/s12070-014-0807-2. 